\title{
ESPAÇO E SUBJETIVIDADE: ENTRELAÇAMENTOS ENTRE SUJEITOS E FAVELA EM BECOS DA MEMÓRIA, DE CONCEIÇÃO EVARISTO
}

SPACE AND SUBJECTIVITY: THE RELATIONS BETWEEN SUBJECTS AND SHANTY TOWN IN BECOS DA MEMÓRIA, BY EVARISTO CONCEICÃO

ESPACIO Y SUBJETIVIDAD: LAS ENTREMEZCLAS ENTRE LO SUJETOS Y LA FAVELA EN BECOS DA MEMÓRIA, DE CONCEICÃO EVARISTO

Ariane Avila Neto de FARIAS

\section{RESUMO}

O presente trabalho visa analisar aspectos referentes ao espaço na obra Becos da Memória (2017), da autora Conceição Evaristo. Entendese que a favela, lugar em que o romance é ambientado, ocupa papel de fundamental importância na construção de tal narrativa, agindo na representação das personagens negras e, principalmente, na construção das fortes mulheres na escrita de Evaristo. Ela é lugar tanto de pertencimento quanto de trânsito dos individuos, reforçando a ideia de que os espacos por onde os sujeitos passam são organizados, tendo como base suas experiências e trocas com o seu corpo. Nesse sentido, ao dar voz ao "espaço-favela", as personagens da narrativa acabam por retirar o véu que cobre os sujeitos marginalizados, dando, assim, voz às diferenças. Tais reflexões serão realizadas a partir de apontamentos de importantes teóricos que pensam o espaço como elemento de uma história, fundamento de caráter inseparável ao indivíduo narrado.

\section{PALAVRAS-CHAVE:}

Espaço; Literatura Brasileira; Favela; Sujeito.

\section{ABSTRACT}

The present paper aims to analyze aspects related to the space in the book Becos da Memória (2017), by the author Conceição Evaristo. It is understood that the shanty town, where the novel is set, occupies a role of fundamental importance in the construction of such narrative, acting in the representation of the black characters and, especially, in the construction of the strong women in the Evaristo's writing. It is a place of both belonging and transit of individuals, reinforcing the idea that the spaces where the subjects pass are organized based on their experiences and exchanges with their body. In this sense, by giving voice to the "space-shanty town", the characters of the narrative end up removing the veil that covers the marginalized subjects, thus giving voice to the differences. Such reflections will be made from notes of important theoreticians who think the space as an element of a story, a foundation of character inseparable from the narrated individual.

\section{KEYWORDS:}

Space; Brazilian Literature; Shanty Town; Subject.

\section{RESUMEN}

El presente trabajo busca analizar aspectos referentes al espacio en la obra Becos da Memória (2017), de la autora Conceição Evaristo. Se entiende aqui que la favela, lugar en que la novela es ambientada, ocupa un papel de fundamental importancia en la construcción de la narrativa, actuando en la representación de las personajes negras $y$, principalmente, en la construcción de las fuertes mujeres en la escritura de Evaristo. Es lugar tanto de pertenencia y de tránsito de los individuos, reforzando la idea de que los espacios por donde los sujetos pasan se organizan teniendo como base sus experiencias e intercambios con su cuerpo. En ese sentido, al dar voz al "espacio-favela", los personajes de la narrativa acaban por quitar el velo que cubre a los sujetos marginados, dando asi voz a las diferencias. Tales reflexiones serán realizadas a partir de apuntes de importantes teóricos que piensan el espacio como elemento de una historia, fundamento de carácter inseparable al individuo narrado.

PALABRAS-LLAVE:

Espacio; Literatura Brasileña; Favela; Sujeto. 


\section{INTRODUÇÃO}

Pensar acerca do sujeito é refletir sobre os diversos aspectos que envolvem a formação de sua subjetividade. Gênero, classe social e raça bem como memórias, traumas e trajetórias são alguns dos elementos que constituem os diversos "eus" em toda a sua complexidade e individualidade. Fluidas e não mais fixas, observa-se cada vez mais o deslocamento das identidades. Nesse sentido, a partir do entendimento da multiplicidade de experiências e das inter-relações como fatores importantes para a compreensão do indivíduo, é que se torna fundamental olhar para os elementos externos que constroem os espaços por onde os sujeitos transitam. Atentar para isto é perceber traços da formação de subjetividades mais plurais e, ao mesmo tempo, mais politizadas, sendo esse aspecto também categoria para a compreensão do mundo.

É no romantismo que as noções referentes ao espaço passam a ter destaque nos processos de análise das diferentes obras literárias. É relevante observar o afirmado por David Lodge (2011) de que "[o romantismo] é o grande responsável pela ponderação dos "efeitos [do ambiente] sobre o homem" (LODGE, 2011, p. 67), abrindo os olhos do mundo "para a beleza sublime das paisagens naturais [...]" (LODGE, 2011, p. 67). Tomando essa afirmação como verdade, a sentença constitui-se, não apenas em seu sentido vinculado à paisagem ou ao retrato, mas como lugar de empoderamento e formação de subjetividade. É dessa maneira que se entende tal elemento "para além de sua vivência” (BRANDÃO, 2013, p. 05)

Na contemporaneidade, os estudos sobre o espaço ganham ainda destaque e demarcam profundamente sua função social, cultural e política ao pensar acerca dos "eus" que a todo o momento se movem. Refletir acerca do espaço narrativo é também teorizar sobre as diferentes classes, etnias, gêneros e corpos, as diversas formas de demonstração de afeto, bem como sobre o sentimento de pertencimento. O espaço geográfico é concebido como um produto social e histórico que possibilita a análise da realidade tanto em sua dimensão material quanto em sua representação. Destarte, é possível afirmar que a atualidade apresenta novas formas de mobilidades e muitas rupturas com o até então concebido moral e socialmente e, a geografia "faz projeções - imaginárias, cartográficas, militares, econômicas, históricas ou, em sentido geral, culturais. Isso possibilita a construção de vários tipos de conhecimento" (SAID, 1995, p. 118).

A concepção acima apresentada faz do espaço um aliado na representação de sujeitos até então marginalizados. Ao colocar vozes silenciadas em destaque, este lugar se reconfigura em direção à valorização de outras experiências, afinal de contas, como bem pontuado por Foucault, ao comentar o trabalho de Bachelard, "não vivemos num espaço homogêneo e vazio, mas, ao contrário, num espaço todo carregado de qualidades, um espaço que talvez seja povoado de fantasmas" (FOUCAULT, 1984, p. 413). É nesse sentido que se compreende que todos os lugares têm histórias para contar; assim como outros elementos, ele é um meio para se analisar os sujeitos.

Pelo exposto, o presente artigo tem como objetivo analisar aspectos referentes à construção do espaço narrativo na obra Becos da memória (2017), da escritora mineira Conceição Evaristo. Neste trabalho, buscar-se-á refletir acerca dos entrecruzamentos entre as personagens periféricas apresentadas por Evaristo e o espaço-favela. Salienta-se a compreensão do espaço contemporâneo como aquele disposto ao movimento, à mobilidade, e que, consequentemente, conduz a uma reflexão sobre os corpos e mentes que por ele transitam. É também importante salientar que tal análise compreende o espaço como subjetivo, imaginário e fruto da ficcionalidade. Essa reflexão toma como fundamentação teórica, trabalhos de teóricos como Paul Ricouer (2007), Yi-fu Tuan (1983) e Luis Alberto Brandão (2013).

\section{AS RELAÇÕES ENTRE SUJEITOS E ESPAÇO}

Becos da Memória (2017) foi o segundo romance da escritora mineira Conceição Evaristo a ser publicado, que aparece no cenário da literatura brasileira com a publicação de poemas nos Cadernos Negros ainda na década de 1990, e que desde sua primeira narrativa trabalha com o objetivo de dar voz aos subalternos, direcionando o olhar aos "invisíveis". Sua escrita é marcada pela abordagem de temáticas delicadas para a literatura como as questões referentes a gênero e a raça.

A obra aqui analisada foi escrita no período entre o final da década de 1970 e início de 1980, ficando engavetada por longos 20 anos, o que acaba revelando a existência de obstáculos dentro do âmbito literário para publicação da obra que não apenas retrata sujeitos marginalizados, mas foi escrita por alguém que vem das margens. $\mathrm{O}$ romance vai narrar, no transcorrer de suas páginas, a história de diversos personagens moradores de uma favela que está em processo de desfavelamento, ou seja, está sendo destruída para dar lugar a uma construção de "homens ricos". As vozes de Maria Velha, Vó Rita, Negro Alírio, Bondade, Ditinha, Balbina, Filó Gazogênia, Cidinha-Cidoca, Tio Totó e Negra Tuína são de sujeitos que, assim como na primeira narrativa de Evaristo, ocupam os espaços das margens; aqueles que conforme as palavras de MariaNova, a menina que dará voz a indivíduos na narrativa, são "os oprimidos, os miseráveis; em todas histórias, quase nunca eram os vencedores, e sim, quase sempre, os vencidos" (EVARISTO, 2017, p. 63).

É através de uma narrativa fragmentada que se tem acesso às lembranças da época em que a favela foi construída; um passado repleto de esperança e desejos de um lugar que aos poucos vai sendo de todos aqueles que ali chegaram. Pequenos relatos de homens, mulheres, crianças que provam a força dos fragmentos sobre a totalidade e que criam um espaço, que através do tempo, é construído pelos sujeitos; diferentes "eus" que vão também sendo constituídos por esse elemento. Partes que representam narrativas que se completam e que se confundem, mas, que no presente, lhes está sendo tomado em benefício daqueles que pertencem a uma esfera formada pelos indivíduos de maior poder aquisitivo. Maria-Nova relata a tristeza e o desespero da comunidade ao ver o seu único lugar seguro sendo desmantelado, junto a certeza de que mais uma vez esses sujeitos serão apagados, silenciados frente às injustiças sociais.

Os tratores da firma construtora
estavam cavando, arando a ponta
norte da favela. Ali, a poeira se
tornava maior e as angústias
também. Algumas famílias já
estavam com ordem de saída e
isto precipitava a dor de todos 
nós. Cada família que saia, era uma confirmação de que chegaria a nossa vez. Ofereciam duas opções ao morador: um pouco de material, tábuas e alguns tijolos para que ele construísse outro barracão, num lugar qualquer, ou uma indenização simbólica, um pouco de dinheiro. [...] Depois vinha o pior, decorrido o prazo de permanência, nem o dinheiro, nem as tábuas, nem os tijolos, só o nada (EVARISTO, 2017, p. 71).

O excerto, acima apresentado, descreve o grande descaso sofrido pelos sujeitos que na favela habitam. Os responsáveis pelo desmonte daquele espaço, em oposição ao sofrimento dos moradores daquela comunidade, não demonstram preocupação com o futuro dessas pessoas. Para os grandes empresários, a favela está sendo destruída para um bem maior; para o atendimento do crescimento e das necessidades de uma sociedade que preza por um sistema financeiro, gerador de poder, ao mesmo tempo em que esquece os seus iguais. Observa-se um contexto no qual um baixo valor em dinheiro torna-se instrumento suficiente para a compensação do fato de seres humanos estarem sendo retirados de suas casas, e porque não dizer, de suas histórias, representando também a perda de sua identidade. Identidade essa que foi e é concebida a partir do espaço-favela; uma narrativa que todos contribuíram para a construção.

Os fragmentos de histórias vão apresentar os diversos vínculos que foram formados entre os sujeitos e aquele espaço. Relações que foram construídas a partir do momento em que aquele lugar começa a ser construído e entendido como lar pelos primeiros moradores; Totó e Nega Tuína que têm suas histórias narradas por MariaNova. A menina retoma as narrativas das mencionadas personagens, descrevendo o momento em que elas chegam à cidade, ao mesmo tempo em que recupera as memórias de uma época em que todas as expectativas apontavam para um futuro melhor no lugar em que acabavam de chegar, conforme narrado por Tio Totó:

[...] Vinha sabendo onde iria ficar. Um amigo estava esperando por eles. Tinha dinheiro suficiente que dava para comprar um barraco. [...] Aqui na capital carece da gente aprender um modo novo de viver... Quando cheguei na favela, ainda tinha muito lugar vazio. Essa minha casa era só um quartinho, fui aumentando aos poucos. Hoje você vê, menina, são quatro cômodos; comecei com Nega Tuína (EVARISTO, 2017, 89).

O excerto acima sugere o papel social significativo que Maria-Nova empenhará no momento em que narra histórias de pessoas simples que, em seu discurso, externalizam o cuidado e a crença em um mundo melhor, além de uma preocupação constante com o outro. As vozes de todos que ali vivem ecoam na menina que percebe que sua narração irá perpetuar as histórias daquele lugar; um espaço que logo será esquecido, tendo em vista que os que ali moram em nada interessam à cidade que cresce. São histórias como as de Tio Totó, um dos primeiros habitantes do local, que Maria-Nova precisa conservar para lembrar, àqueles que naquele espaço não mais estarão, a importância do conhecimento de suas origens.

Dessa maneira, ao dar voz aos que vivem ali, Maria-Nova descreve uma história de permutação entre espaço e sujeitos, uma narrativa de trocas, de reconhecimento e de pertencimento. Nas histórias expostas, a narradora vai ao encontro do afirmado por Santos: "o espaço deve ser considerado com um conjunto indissociável de que participam, de um lado, certo arranjo de objetos geográficos, objetos naturais e objetos sociais, e, de outro, a vida que os preenche e os anima, seja a sociedade em movimento" (SANTOS, 1986, p. 10).

Nessa perspectiva, o espaço narrado vai evidenciar o total apagamento de indivíduos marginalizados e esquecidos, que podem ser "jogados" de um lado para outro por aqueles que ocupam lugares sociais privilegiados. Ao se pensar nos problemas enfrentados na favela narrada, que nas palavras de um dos personagens apresentada por Maria-Nova é "grande como uma cidade" (EVARISTO, 2017, p. 24), se faz também necessária a reflexão acerca dos problemas que batem às portas das mais variadas cidades brasileiras. Conforme narrado por Maria-Nova, são diversas as localidades e sujeitos no Brasil que sofrem com a mesma realidade de esquecimento.

Michel Foucault afirma que, “o espaço é fundamental em qualquer forma de vida comunitária" (FOUCAULT, 1984, p. 252). Ele aponta, assim, que esse é importante para se refletir sobre a constituição de regras, limites e parâmetros para o conviver em sociedade. $\mathrm{O}$ espaço, para Foucault, também é elemento de demarcação dos jogos de poder que gerem o social; é desse modo que a favela vai trabalhar, na escrita de Evaristo, como o retrato daqueles sujeitos marginalizados; indivíduos sem voz e força diante de um jogo de dominantes. O desmonte desse espaço representa ainda o esfacelamento e a dor das pessoas moradoras dos diversos barracos que o constituem; a confirmação do não pertencimento daqueles que vivem à margem dos movimentos do desenvolvimento do capitalismo. Estes indivíduos não são considerados protagonistas deste crescimento, mas mão-de-obra barata para o progresso deste poder.

Os desastres vivenciado por cada um dos moradores em nada se comparam ao momento em que vivem a perda coletiva do lugar para o qual voltam todos os dias após a luta diária diante de uma sociedade desigual. Perder a favela é perder um pedaço do que são; na medida em que não se tem mais os que se ama por perto, afastando-se daquilo que ajudaram a construir e que os ajudou em sua construção; perder "um lugar de que eu já pensava ser dono" (EVARISTO, 2017, p. 29). As palavras de Maria-Nova confirmam a dificuldade que é imaginar um tempo sem o espaço que eles chamam de lar, importante e fundamental para a constituição dos seus "eus": "todos sabiam que a favela não era o paraíso, mas ninguém queria sair. Ali perto estava o trabalho, a sobrevivência de todos. [...] Aqueles tratores trariam tanta tristeza, trariam desgraça até" (EVARISTO, 2017, p. 72).

O teórico Paul Ricouer (2007), ao discorrer sobre questões acerca da constituição da memória, aponta para a relação significativa construída entre os sujeitos e os espaços os quais habitam. A partir dos apontamentos do estudioso francês, compreende-se que os diferentes laços criados por esse encontro colocam as questões referentes ao espaço em um lugar tão importante quanto os demais elementos narratológicos, já que ele é um dos principais meios de reflexão das qualidades, sentidos e lembranças do 
sujeito, tanto em sua individualidade, quanto na sua coletividade. $\mathrm{O}$ pesquisador afirma:

as lembranças de ter morado [...] em tal cidade ou de ter viajado a tal parte do mundo são particularmente eloquentes $e$ preciosas, elas tecem ao mesmo tempo uma memória intima $e$ uma memória coletiva [...] nessa lembranças, o espaço corporal é de imediato vinculado ao espaço do ambiente (RICOUER, 2007, $p$. 157).

O excerto acima reforça a indissociabilidade entre sujeitos e espaços os quais fazem parte; "há a impossibilidade da desvinculação entre espaço e corpo, ao sublinhar o vínculo do segundo à percepção e à esfera do sensível" (BRANDÃO, 2013, p. 57). Verificase, dessa forma, que o olhar espacial supõe olhar a realidade sociocultural, verificando as marcas dos mais variados dispositivos inscritos nesse espaço, sugerindo, o assinalado por Callai, de que é no "[...] cotidiano da própria vivência que as coisas vão acontecendo e, assim, configurando o espaço, dando feição ao lugar" (CALLAI, 2009, p. 234-235).

Nesse mesmo sentido, pontua Callai (2009) que o espaço construído é resultado da história das pessoas, dos grupos que nele vivem, como trabalham, se alimentam e usufruem do lazer. Isto resgata a identidade, e neste processo, é muito importante reconhecer os vínculos afetivos que ligam as pessoas aos lugares. Esses vínculos, para Ricoeur (2007), acabam influenciando na constituição de uma memória e consciência coletiva. $\mathrm{O}$ pertencimento a um espaço e a um grupo faz com que os sujeitos definam suas identidades a partir de experiências que são compartilhadas. Dessa forma, os moradores da favela desmantelada, na narrativa de Conceição, constituíamse em "gerações inteiras [que] nasciam e cumpriam tempo de vida acostumados à miséria, fazendo muitas das misérias razão da vida" (EVARISTO. 2017, p. 141) e, assim, são eles as memórias e as histórias - mortes, nascimentos, brigas, amigos, choros e sorrisos - desse lugar que serão apagados, evidenciando o desprezo social por quem ali mora.

O espaço urbano, no auge de seu desenvolvimento, diferente daquele micro espaço configurado pela favela, rejeita os indivíduos que para ele não estão suficientemente preparados para a vida da atualidade, e toda a rapidez e avanços que a acompanham. Ao apagar o espaço da margem, o centro confirma que os sujeitos marginalizados não possuem vidas verdadeiramente suas, mas sim, vidas que não dependem de suas vontades. Nessas relações de poder, os barracos e seus moradores, em nenhum aspecto, ganham. Os grupos do centro acabam normalmente sendo os que vencem, realidade comum e que faz parte da história dos indivíduos das margens; situação que acaba sendo repetida de geração em geração, conforme Evaristo (2017) retrata no trecho em que mostra Maria-Nova e suas conclusões sobre o espaço em que vive, bem como sobre os sujeitos com quem convive:

Mas a menina é do tipo que gosta de pôr o dedo na ferida, não na ferida alheia, mas naquela que ela traz no peito. Na ferida que ela herdou de Mãe Joana, de Maria-Velha, de Tio Totó [...] o que doía mesmo em MariaNova era que tudo se repetia, um pouco diferente, mas, no fundo, a miséria era a mesma. O seu povo, os oprimidos, os miseráveis; em todas as histórias, quase nunca eram os vencedores, e sim, quase sempre os vencidos. A ferida dos do lado de cá sempre ardia, doía e sangrava muito (EVARISTO, 2017, p. 63).

O trecho acima sugere uma história que identifica os sujeitos marginalizados como os que carregam consigo marcas de um passado doloroso que sempre deixou evidente o apagamento a que esses foram submetidos. Entretanto, tanto sofrimento parece estar longe de acabar e se intensifica com o processo de desfavelamento que pretende retirar os indivíduos das margens de um espaço que sempre identificaram como seu e que acabava os definindo. A desconstrução desse espaço, no qual pessoas esmorecem e, até mesmo, morrem, acentua a ideia de que refletir acerca desse lugar e de seu encontro com as questões referentes à construção da subjetividade, significa destacar uma sociedade hierarquizada. Os moradores da favela têm ainda mais certeza que certas vidas valem mais do que outras.
A possibilidade de alegrias, a inocência dos que moram no espaço que se apaga, e mesmo a certeza de que nada irá mudar o destino, faz com que os moradores utilizem as próprias máquinas, deixadas no lugar dos barracos já destruídos, como forma de divertimento. Nenhum tipo de cuidado é tomado pela empresa responsável pelo processo de desfavelamento, que não pesa os perigos que todos correm, deixando-os à mercê de constantes riscos; as máquinas ficam expostas e denotam o total descaso para com essas pessoas. O trágico mais de uma vez acontece, evidenciando a morte já anunciada pela pobreza: uma vez com os "homens-vadios-meninos", que durante a noite, após muito beberem, enxergam naqueles equipamentos a possibilidade de aproveitarem o "prazer que não tiveram na infância", (EVARISTO, 2017, p. 74), fato que acaba levando-os a morte. Por outro lado, o caso do menino Brandino demonstra que a tragédia causada ao jovem se tornou o ganha pão de sua família,

Foi isso que aconteceu. Brandino vinha viando, leve, voando como uma pluma. O trator ali parado, pesadão. $O$ rosto, o corpo, o menino frágil. Não a morte instantânea, rápida, como havia acontecido com os homensvadios-meninos, não houve. Brandino foi para o hospital, ficou meses. Voltou sim, calado, mortovivo, bobo, alheio, paraliticos. A mãe pegava o menino, colocava num carrinho de madeira, pegava os três menores e saía a pedirganha esmolas (EVARISTO, 2017, p. 80).

Os infortúnios narrados marcam a fragilidade daqueles que moram na favela diante da grandiosidade da empresa que deles toma o espaço. Uma violência extrema que sinaliza o fim da favela e demarca um "caminho marcado pela observação das mazelas de um projeto urbano que não consegue solucionar a demanda dos excluídos" (FONSECA, 2017 , p. 192) e que em suas atitudes busca mostrar um poder sempre maior que o dos moradores da favela, como sugere a situação resposta ao motim que exige a retirada dos tratores, organizada por Negro Alírio, após o acidente de Brandino, "[...] novos tratores chegaram. Chegaram bravios, recomeçando o trabalho. Só se ouvia barulho e sentia 
poeira. O desfavelamento recomeçava" (EVARISTO, 2017, p. 81).

\section{A ESCRITA, O ESPAÇO E OS SUJEITOS: MEMÓRIAS DE UM PASSADO QUE NÃO PODE SER ESQUECIDO}

É nesse cenário de perdas que MariaNova reconhece a força da escrita como importante instrumento de preservação das memórias do espaço-favela e dos sujeitos-favelados. A escrita funciona como uma possibilidade de registro de uma realidade difícil, mas que precisa ser narrada para que se transforme em uma forma de denúncia da árdua realidade enfrentada por quem está nas margens. É preciso dar voz aos invisíveis e retratar as memórias de uma coletividade que compartilha as mesmas lutas e anseios:

Sim, ela iria adiante. Um dia, agora ela já sabia qual seria a sua ferramenta, a escrita. Um dia, ela haveria de narrar, de fazer soar, de soltar as vozes, os murmúrios, os silêncios, o grito abafado que existira, que era de cada um e de todos. Maria-Nova escreveria a fala de seu povo (EVARISTO, 2017, p. 177).

Logo, Maria-Nova percebe na escrita uma forma de expor a fala de um grupo que foi constituído a partir de um lugar de exclusão. Sua linguagem escrita em pedaços revela muito sobre a sensação de pertencimento àquele espaço, bem como acerca das trocas ocorridas entre os sujeitos da favela e o local que eles reconhecem como sendo pertencentes. Nesse sentido, é fundamental que a história construída por esse povo seja contada a partir de um olhar que realmente os compreenda e seja capaz de expressar a complexidade das relações ali estabelecidas.

Em Becos da Memória (2017), a discussão sobre a relevância da escrita acaba por evidenciar que tradicionalmente temos acesso a um olhar expresso pelo centro, um olhar que não é capaz de exprimir a verdadeira realidade dos que não fazem parte do grupo que detém o poder. Nesse sentido, sobre o potencial da escrita de Maria-Nova, afirma Simone Schmidt, que “dar corpo à memória dos moradores da favela, caminhando a memória em sentido contrário aos estereótipos que se colam à pele dos subalternos em nossa sociedade, é, portanto, uma estratégia de grande impacto político e cultural" (SCHMIDT, 2017, p. 186). É isso que acontece quando Maria-Nova, na aula sobre história e libertação dos escravos, percebe que teria tanto para falar sobre escravos e libertação que "[...] teria para contar muitas vidas." (SCHMIDT, 2017, p. 150), mas seria uma história diferente da de sua professora, pois para ela era preciso contar sobre " [...] uma senzala de que, hoje, seus moradores não estavam libertos, pois não tinham nenhuma condição de vida" (SCHMIDT, 2017, p.150). É revelada, então, a necessidade de se contar/escrever uma história que reflita acerca das condições de vida desses sujeitos:

Era uma História muito grande! Uma História viva que nascia das pessoas, do hoje, do agora. Era diferente de ler aquele texto. Assentou-se e, pela primeira vez, veio-lhe um pensamento: quem sabe escreveria esta história um dia? Quem sabe passaria para o papel o que estava escrito, cravado e gravado no seu corpo, na sua alma, na sua mente (EVARISTO, 2017, p. 150-151).

Assim, Maria-Nova não estaria contando uma história qualquer, mas sim uma narrativa que estava gravada no seu corpo e alma, uma vez que fazia parte do passado de seu povo. Uma história que havia sido construída dentro de espaços específicos e que agora apresentava continuidade dentro da favela. Todavia, o fato de estar sendo obrigada junto com sua família e amigos a deixar esse espaço, faz com que aflore o sentimento de perda de identidade e de sensação de pertencimento. Discutir sobre memória é também discorrer sobre espaços que permeiam a constituição dos sujeitos.

É no processo de escrita que MariaNova encontra uma forma de narrar a história de seu lugar; um "espaço social que não conhece as grandes avenidas, as ruas abertas em obediência a um plano arquitetônico" (FONSECA, 2017, p. 196), e que, ao mesmo tempo, visa transformar isso em uma tentativa de preservar uma memória que é de seus antepassados e das gerações que ainda virão. Além disso, a escrita das breves histórias narradas por Maria-Nova traça a estrutura sinuosa e multifacetada de um espaço que pode ser compreendido para além de seu papel de suporte aos sujeitos da narrativa (palco), protagonizando a função de veículo (ator) de um processo que está em constante movimento de lutas entre o já existente e o que impõe sua existência; o espaço é então participante ativo na narrativa, fazendo-se componente relevante de análise. Entende-se que ele propicia um conjunto de atuações para a consolidação das relações que se estabelecem entre os sujeitos que ali vivem, representados por suas histórias.

\section{CONSIDERAÇÕES FINAIS}

O presente artigo buscou analisar de que maneira espaço e sujeitos se relacionam na narrativa da escritora Conceição Evaristo (2017). Compreende-se, a partir dos elementos analisados, a importância do espaço para a construção narrativa de Becos da Memória (2017). Deste modo, tomando como base os teóricos citados, considera-se que a visão do local o qual estão inseridas as personagens de um romance é fator crucial para o entendimento da narrativa de Evaristo. Assim, tem-se um espaço que atinge todos os sentidos humanos, que valoriza e auxilia na construção da subjetividade de todos que nele estão.

Nesse sentido, ao escrever a favela memórias e sujeitos -, Maria-Nova a configura como um lugar que carrega a intensa dramaticidade e constante busca pela razão da existência. Maria-Nova apresenta um espaço que constantemente se entrecruza aos indivíduos que nele residem. Ao colocar esse espaço no centro de sua literatura, Evaristo (2017) evidencia a importância de se olhar para aqueles que há tanto são esquecidos e abandonados pelo centro detentor de poder; por um centro que os limita.

Por fim, percebe-se a valorização do espaço-favela como um elemento que organiza a narrativa, colocando em 
evidência os que vivem nele e formando uma estrutura que não se dissolve, mas que se completa. O espaço-favela, elaborado por Evaristo (2017) não apenas discorre sobre suas especificidades, mas representa uma marca de sua elaboração literária ao mostrar-se constituído por um campo de (re)combinações de significados, bem como de subjetividades.

\section{REFERENNCIAS}

BACHELARD, Gaston. A poética do espaço. Tradução de Antonio de Pádua Danesi. 2ed. São Paulo: Martins Fontes, selo Martins, 2008.

\section{BRANDÃO, Luis Alberto. "Breve} história do espaço na teoria da literatura". In: Cerrados: Revista do Programa de Pós-Graduação em Literatura, n. 19, ano 14, p. 115-134, 2005.
BRANDÃO, Luis Alberto. Teorias do espaço literário. Belo Horizonte: Perspectiva, 2013

CALLAI, Copetti Helena. Estudar o lugar para compreender o mundo. In: CASTROGIOVANI, Antônio Carlos (org). Ensino de Geografia: práticas e textualizações no cotidiano. Porto Alegre: Mediação, 7 ed.Cap 2. p 83134, 2009.

\section{EVARISTO, Conceição. Becos da} memória. Rio de Janeiro: Pallas, 2017. FONSECA, Maria Nazareth Soares. "Posfácio: costurando uma colcha de memória". In: EVARISTO, Conceição. Becos da memória. Rio de Janeiro. Pallas, 2017

FOUCAULT, Michel. Space, knowledge and power. In: RABINOW, Paul. The Foucault Reader. London: Penguin Book, 1984
LODGE, David. A arte da ficção: tradução de Guilherme da Silva Braga. Porto Alegre: L\&PM, 2011.

RICOUER, Paul. A memória, a história o esquecimento. Campinas: Unicamp. 2007.

SAID, Edward. Cultura e imperialismo: tradução de Denise Bottman. São Paulo: Companhia das Letras, 1995.

SANTOS, Milton. Pensando o espaço do homem. São Paulo: Hucitec, 1986.

SCHMIDT, Simone Pereira. "Posfácio: a força das palavras, da memória e da narrativa". In: EVARISTO, Conceição. Becos da Memória. Rio de Janeiro. Pallas, 2017.

SOUZA, Marcelo J.L. de. Espaciologia uma objeção. In: O Espaço em Questão. São Paulo: Terra Livre, no 5, 1988.

\section{Recebido em 28 Jan 2019 | Aprovado em 12 Jun 2019}

Ariane Avila Neto de FARIAS

Doutoranda em Letras, na área de História da Literatura da Universidade Federal de Rio Grande (FURG). Possui graduação em Letras pela Universidade Federal do Pampa (2011) e mestrado em Letras pela Universidade Federal de Pelotas (2017). Atualmente é assistente em administração da Universidade Federal do Pampa. E-mail: arianeaneto@hotmail.com 